\title{
Seed rain and soil seed banks in Chinese fir plantations and an adjacent natural forest in southern China: implications for the regeneration of native species
}

\author{
Bo Liu ${ }^{1}$, Qingqing Liu ${ }^{2}$, Chenxi Zhu², Zhigang Liu ${ }^{3}$, Zhijun Huang ${ }^{2}$, Mulualem Tigabu ${ }^{4}$, \\ Zongming $\mathrm{He}^{2}$, Yuhui Liu ${ }^{5}$, and Zhengning Wang ${ }^{1}$ \\ ${ }^{1}$ Qufu Normal University \\ ${ }^{2}$ Fujian Agriculture and Forestry University \\ ${ }^{3}$ Forestry bureau of Xinxiang \\ ${ }^{4}$ Swedish University of Agricultural Sciences \\ ${ }^{5}$ Xinkou Teaching Forest Farm, Fujian Agriculture and Forestry University
}

October 1, 2021

\begin{abstract}
The natural regeneration of native broadleaved species underneath forest monoculture plantations is important to recover ecosystem functions and to mitigate adverse environmental effects. To understand how seed rain and soil seed banks facilitate natural regeneration, we surveyed their density and composition in a monoculture Chinese fir plantation, a mixed Chinese fir-broadleaf plantation, and an adjacent natural broadleaved forest for two years in southern China. Twenty-eight species (16 families) were in seed rain, and 45 species (27 families) were in soil seed banks. Seed rain density did not differ significantly across stands; however, the number of taxa in seed rain was highest in the mixed plantation and lowest in the natural forest. Seed bank density was significantly higher in the mixed plantation than in the other stands. The Sørensen similarity indices of species composition between seed sources and aboveground vegetation were relatively low $(<0.50)$. In addition, the seeds of native tree species common to the seed banks of the three forests indicated the adjacent natural forest was a seed source for the natural regeneration of native species in forest plantations. To augment regeneration and accelerate the rate of conversion, we recommend direct seeding or planting of desired species.
\end{abstract}

\section{Hosted file}

Ecology and Evolotion-9.24.docx available at https://authorea.com/users/438951/articles/ 540012-seed-rain-and-soil-seed-banks-in-chinese-fir-plantations-and-an-adjacent-naturalforest-in-southern-china-implications-for-the-regeneration-of-native-species 